Article

\title{
Chitosan-Based Coating Enriched with Hairy Fig (Ficus hirta Vahl.) Fruit Extract for "Newhall" Navel Orange Preservation
}

\author{
Chuying Chen ${ }^{1}$, Nan Cai ${ }^{1}$, Jinyin Chen ${ }^{1,2, *}$, Xuan Peng ${ }^{2}$ and Chunpeng Wan ${ }^{1, *(1)}$ \\ 1 Jiangxi Key Laboratory for Postharvest Technology and Nondestructive Testing of Fruits \& Vegetables, \\ Collaborative Innovation Center of Postharvest Key Technology and Quality Safety of Fruits and Vegetables, \\ Jiangxi Agricultural University, Nanchang 330045, China; cy.chen@jxau.edu.cn (C.C.); \\ wq1252733770@163.com (N.C.) \\ 2 Pingxiang University, Pingxiang 337055, China; pengx1104@163.com \\ * Correspondence: jinyinchen@126.com (J.C.); chunpengwan@jxau.edu.cn (C.W.); \\ Tel.: +86-791-8381-3158 (J.C. \& C.W.)
}

Received: 25 October 2018; Accepted: 4 December 2018; Published: 4 December 2018

\begin{abstract}
A novel coating based on $1.5 \%$ chitosan $(\mathrm{CH})$, enriched with or without hairy fig (Ficus hirta Vahl.) fruit extract (HFE), was applied to "Newhall" navel orange for improving the preservation effect. Changes in physicochemical indexes were analyzed over 120 days of cold storage. Uncoated fruit were used as the control. The CH-HFE coating, based on $1.5 \% \mathrm{CH}$ enriched with HFE, exhibited the best preservation effect and showed the lowest decay rate $(5.2 \%)$ and weight loss $(5.16 \%)$. The $\mathrm{CH}-\mathrm{HFE}$ coating could postpone the ripening and senescence of navel oranges, and maintain higher fruit quality by inhibiting respiration, decreasing the accumulation of malondialdehyde (MDA), and enhancing the activities of protective enzyme, including superoxide dismutase (SOD), peroxidase (POD), chitinase (CHI), and $\beta$-1,3-glucanase (GLU), which suggests that $\mathrm{CH}-\mathrm{HFE}$ coating has the potential to improve the postharvest quality of "Newhall" navel orange and prolong the storage life.
\end{abstract}

Keywords: chitosan; edible coating; hairy fig fruits; navel oranges; physicochemical responses

\section{Introduction}

"Newhall" navel orange (Citrus sinensis L., Osbeck) fruits enjoy great popularity in China and around the world, for their good taste, abundant vitamin, $\mathrm{C}$ and widespread availability [1]. However, there are serious problems restricting the sound development of citrus production. Postharvest losses, frequent decay caused by a variety of plant pathogenic fungi, and a lack of scientific management, are issues of concern that need to be solved; of these, postharvest decay is the biggest hurdle that needs urgent resolution.

Pathogen infection is an important factor that affects citrus fruit postharvest physiology, disease resistance, and metabolism. Blue and green mold of citrus, caused by Penicillium italicum and Penicillium digitatum, respectively, are the most economically important postharvest diseases of citrus, and cause heavy losses during storage, transportation, and marketing, thus debasing the commodity value of harvested fruits [2]. The two Penicillium molds may cause $60 \%-80 \%$ decay losses under ambient conditions [3], which leads to severe economic losses for exporting countries. At present, the primary means for controlling of the two Penicillium molds still relies mainly on the use of chemical fungicides, especially imazalil (IMZ), prochloraz, thiabendazole (TBZ), calcium polysulfide pyrimethanil, or different mixtures of these compounds [4-7]. Increasing public concern of chemical residues on human health and environmental pollution, due to excessive use of chemical fungicides, 
have prompted investigation of alternative strategies for reducing postharvest decay and maintaining citrus fruit postharvest quality, without any human, environmental, or plant toxicity [8-10]. A variety of plant-derived compounds have been recognized and generally regarded as safe (GRAS) substances for their antifungal activities, and are being used for controlling postharvest fungal rotting of fresh horticultural products [11-13]. In recent years, numerous researchers have documented the antifungal effects of plant extracts or essential oils for reducing postharvest disease development caused by pathogenic fungus, leading to heavy losses and serious deterioration of citrus fruits [14-17].

The hairy fig is a deciduous plant widely distributed in southern China as a traditional plant resource used as medicinal and edible food by Hakka people. It is a clearly recognizable plant for its five-fingered leaf shape and mature fruit that resembles wild peach (Figure 1). Moreover, the fruits of hairy fig are a famous herb used by Hakka people in Chinese folk medicine for inhibiting tumor growth, promoting lactation, as anticoagulant, and for improving fatigue resistance [18,19]. Currently, our previous research demonstrated that HFE has strong antifungal activity against $P$. italicum and $P$. digitatum in vitro conditions $[20,21]$. Not surprisingly, chitosan coating enriched with HFE provided an enhanced antifungal activity, and it is likely that research will broaden the practicability of the botanical fungicide. Development of antimicrobial/antioxidant coatings from polysaccharides, such as chitosan, have been studied extensively, whereas few works have been conducted on developing films using the combination of chitosan and natural plant extract-based antifungal components. The purpose of this research was to evaluate the effect of chitosan coating enriched with or without HFE for cold-stored navel orange preservation.

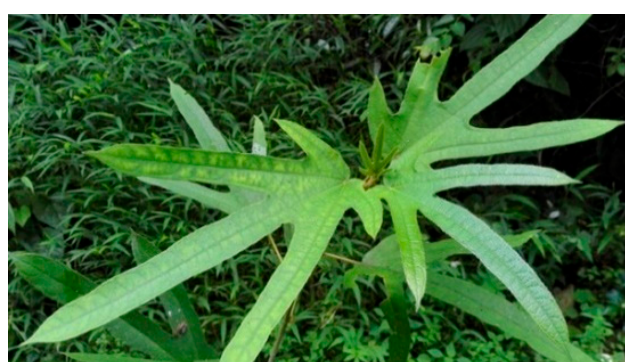

(A)

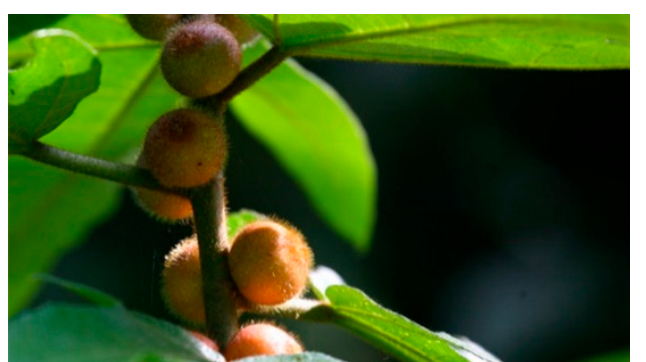

(B)

Figure 1. The (A) leaves and (B) fruits of hairy fig (Ficus hirta Vahl.).

\section{Materials and Methods}

\subsection{Materials}

Fruits of navel oranges (Citrus Sinensis L. Osbeck cv. Newhall), used throughout this study, were harvested at the peak of the harvesting season from an orchard situated in the southeast of Ganzhou city (Jiangxi, China). The fruits were picked on the basis of consistent size (240-280 g) and uniform color (citrus color index, 3.5-4.8). Fruits with any mechanical injury, blemish, or diseases were discarded.

\subsection{Extraction of HFE}

The fruits of hairy fig (origin: Guangdong, China) were purchased from Huafeng herbs store in Zhangshu (Jiangxi, China) and powdered in a grinder (less than 20 mesh) after drying below $40{ }^{\circ} \mathrm{C}$. The HFE was obtained using an ultrasonic-assisted method, as described below [21]. The air-dried mixture of $100 \mathrm{~g}$ powder sample was suspended in $3.1 \mathrm{~L} 90 \%$ ethanol $(v / v)$ at $51{ }^{\circ} \mathrm{C}$ with ultrasonic-assisted extraction $(40 \mathrm{kHz})$ for $65 \mathrm{~min}$. The HFE was filtered and concentrated by vacuum distillation at $45^{\circ} \mathrm{C}$, using a Buchi rotary evaporator (R210, Buchi, Labortechnik AG, Flawil, Switzerland). The remaining solution was dissolved in sterile water and made up to $100 \mathrm{~mL}$ at a concentration of $1 \mathrm{~g} \mathrm{~mL}^{-1}$ (raw herb/solvent, $w / v$ ), then stored at $4{ }^{\circ} \mathrm{C}$ for further use. 


\subsection{Preparation of $\mathrm{CH}-\mathrm{HFE}$ and Chitosan Coatings}

Chitosan solution $(1.5 \%, w / v)$ was prepared by dissolving $15.0 \mathrm{~g}$ of chitosan (the degree of deacetylation of 90\%, Sinopharm Chemical Reagent Co., Ltd., Shanghai, China) in $800 \mathrm{~mL}$ of acetic acid solution $(0.5 \%, v / v)$. Crude HFE extract $(35 \mathrm{~mL})$ was put into the coating, with agitation for $1 \mathrm{~h}$. The $\mathrm{pH}$ of the solution was adjusted with $1.0 \mathrm{M} \mathrm{NaOH}$ to $\mathrm{pH} 5.4$, and the total volume of the solution was made up to $1000 \mathrm{~mL}$. Chitosan coating of the same concentration $(1.5 \%, w / v)$ was prepared in the same way.

\subsection{Navel Orange Treatment and Storage}

The selected fruits were washed with tap water and air-dried at room temperature $\left(25 \pm 1^{\circ} \mathrm{C}\right)$, then coated by dipping in chitosan coating and/or HFE for $1 \mathrm{~min}$ (CH-HFE and 1.5\% chitosan coating, respectively), while the control group was dipped in $0.5 \%$ acetic acid solution ( $\mathrm{pH} 5.4$ ). After drying, the coated, as well as control, fruits were individually film $(18 \mathrm{~cm} \times 15 \mathrm{~cm}$, Lingqu fresh packaging products Co. Ltd., Guilin, China)-packaged and pre-cooled $\left(10-12{ }^{\circ} \mathrm{C}, 12 \mathrm{~h}\right)$. Finally, all fruits were stored at $5 \pm 0.5^{\circ} \mathrm{C}$, and $85 \%-90 \%$ relative humidity (RH) for 120 days. The procedures for the coating and control group were performed three times of total 560 navel oranges per treatment. At each sampling point $(15,30,45,60,75,90,105$, and 120 days), each replicates of 10 navel oranges were randomly picked out from the coating and control group for analyzing total soluble solid (TSS) content, titratable acid (TA) content, vitamin C (VC) content, total sugar content, respiration rate, MDA content, as well as protective enzyme activities.

\subsection{Measurement of Physicochemical Indexes}

Fruit decay rate was visually evaluated using the same 80 navel oranges per treatment per replicate, during the storage period of semi-monthly, and expressed as the percentage of rotted fruits. Navel oranges with apparent disease spots were considered to be decayed. Weight loss was measured by weighing the same 20 fruits during storage every 15 days, and the data are means of 20 samples \pm SE.

TSS, TA, VC, and total sugar were analyzed after completely mixing the orange juice from 10 fruits in the coated and control groups. TSS was measured using a V RA-250 WE digital brix-meter (KYOTO, Tokyo, Japan) and expressed as a percentage. TA and VC were determined by titration with $0.1 \mathrm{M}$ $\mathrm{NaOH}$, and 2,6-dichlorophenol indophenol, respectively. Total sugar content was measured using the anthrone colorimetric method [22].

\subsection{Assay of Respiration Rate and MDA Content}

The respiration rate was determined based on a method described by our previous study [23]. Six fruits, per treatment per replicate, were weighed before being sealed in an airtight plastic container (internal diameter of $27.5 \mathrm{~cm}, 30.0 \mathrm{~cm}$ high) at $25^{\circ} \mathrm{C}$. The increased $\mathrm{CO}_{2}$ concentration in the container was monitored by using a GHX-3051H infrared $\mathrm{CO}_{2}$ fruit and vegetable breathing apparatus (Jingmi Scientific LLC., Shanghai, China). Respiration rate, measured by $\mathrm{CO}_{2}$ production, was expressed as $\mathrm{mg} \mathrm{kg}^{-1} \mathrm{~h}^{-1}$.

The MDA content in coating and control groups was measured according to the method of Hodges et al. [24]. Pericarp tissues from 10 fruits were ground in a MM 400 frozen grinder (Retsch $\mathrm{GmbH}$., Arzberg, Germany), and $2.0 \mathrm{~g}$ of powder were homogenized in $25 \mathrm{~mL}$ of ice-cold $50 \mathrm{mM}$ phosphate buffer (pH 7.8) containing $1 \mathrm{mM}$ EDTA and $2 \%(w / v)$ PVP, and centrifuged at 12,000 $\mathrm{g}(5804 \mathrm{R}$, Eppendorf, Hamburg, Germany) for $20 \mathrm{~min}$ at $4{ }^{\circ} \mathrm{C}$. Afterwards, $2 \mathrm{~mL}$ of the collected supernatant was mixed with $2 \mathrm{~mL}$ of $0.5 \%(w / v)$ thiobarbituric acid (TBA), and further incubated in boiling water for $30 \mathrm{~min}$. After being cooled and centrifuged at $6000 \mathrm{~g}$ (5804R, Eppendorf) for $10 \mathrm{~min}$, the absorbance of supernatant was measured at three different wavelengths $(450,532$, and $600 \mathrm{~nm})$ using a M5 Multiscan Spectrum microplate reader (Molecular Devices Corporation, Sunnyvale, CA, USA). The MDA content 
was calculated according to the formula $\left(6.452 \times\left(A_{532}-A_{600}\right)-0.559 \times A_{450}\right)$, and expressed as $\mathrm{mmol} \mathrm{g}^{-1}$ frozen weight (FW).

\subsection{Determination of Protective Enzymes Activities}

Aliquots of powder $(2.0 \mathrm{~g})$ were homogenized with various ice-cold extraction buffers to prepare extracts for assay of the following protective enzymes: $10 \mathrm{~mL}$ of $50 \mathrm{mM}$ ice-cold phosphate buffer (pH 7.8) containing $1 \mathrm{mM}$ EDTA, $5 \mathrm{mM}$ DTT, and 2\% (w/v) PVP for superoxide dismutase (SOD, EC 1.15.1.1); $8 \mathrm{~mL}$ of $100 \mathrm{mM}$ ice-cold phosphate buffer ( $\mathrm{pH}$ 7.5) containing $1 \mathrm{mM}$ polyethylene glycol (PEG), 4\% (w/v) PVP, and 1\% ( $w / v)$ Triton X-100 for peroxidase (POD, EC 1.11.1.7); $10 \mathrm{~mL}$ of $100 \mathrm{mM}$ ice-cold sodium acetate buffer ( $\mathrm{pH}$ 5.2) containing $5 \mathrm{mM} \beta$-mercaptoethanol, $1 \mathrm{mM}$ PEG, $1 \mathrm{mM}$ EDTA, $4 \%(w / v)$ PVP, and $0.5 \%(w / v)$ Triton X-100 for chitinase (CHI, EC 3.2.1.14) and $\beta$-1,3-glucanase (GLU, EC 3.2.1.73). All homogenates were centrifuged at 12,000 g (5804R, Eppendorf) for $30 \mathrm{~min}$ at $4{ }^{\circ} \mathrm{C}$. The supernatants were then collected and used for the enzyme activity assays.

SOD activity was assayed by measuring its ability to inhibit the photoreduction of nitroblue tetrazolium (NBT) according to the method of Sala and Lafuente, with slight modifications [25]. The reaction mixture consisted of $1.5 \mathrm{~mL}$ PBS $(50 \mathrm{mM}), 0.3 \mathrm{~mL}$ Met $(130 \mathrm{mM}), 0.3 \mathrm{~mL}$ NBT $(0.75 \mathrm{mM})$, $0.3 \mathrm{~mL}$ EDTA-Na $\mathrm{Na}_{2}(0.1 \mathrm{mM}), 0.3 \mathrm{~mL}$ riboflavin $(20 \mu \mathrm{M}), 0.1 \mathrm{~mL}$ enzyme extract, and $0.5 \mathrm{~mL}$ distilled water in a total volume of $3.3 \mathrm{~mL}$. The mixtures were illuminated by light $(4000 \mathrm{Lx})$ for $20 \mathrm{~min}$ at $28^{\circ} \mathrm{C}$, and the absorbance was then determined at $560 \mathrm{~nm}$ (UV-1800, Shimadzu, Tokyo, Japan). One unit of SOD activity was defined as the amount of enzyme that would inhibit $50 \%$ of NBT photoreduction, and expressed as $\mathrm{U} \mathrm{min}^{-1} \mathrm{~g}^{-1} \mathrm{FW}$.

POD activity was based on the determination of guaiacol oxidation at $470 \mathrm{~nm}$ in the presence of $\mathrm{H}_{2} \mathrm{O}_{2}$. Collected supernatant $(100 \mu \mathrm{L})$ was mixed with $3.0 \mathrm{~mL}$ of $25 \mathrm{mM}$ guaiacol and $200 \mu \mathrm{L}$ of $50 \mathrm{mM} \mathrm{H} \mathrm{O}_{2}$. Oxidation of guaiacol was determined at $470 \mathrm{~nm}$ for $3 \mathrm{~min}$ at $25^{\circ} \mathrm{C}$. One unit of POD activity was defined as an increment of 0.01 in absorbance per minute at $470 \mathrm{~nm}$, and expressed as $\mathrm{U} \min ^{-1} \mathrm{~g}^{-1} \mathrm{FW}$.

CHI and GLU activities were assayed by the method described by Abeles et al. [26] using chitinase and laminarin as substrate. One unit of $\mathrm{CHI}$ activity was defined as the amount of enzyme that catalyzed the produce of $1 \mathrm{nmol}$ of $\mathrm{N}$-acetyl-D-glucosamine per hour at $585 \mathrm{~nm}$, and expressed as $\mathrm{U}$ $\mathrm{h}^{-1} \mathrm{~g}^{-1} \mathrm{FW}$. One unit of GLU activity was defined as the amount of enzyme that produced a reducing sugar equivalent to $1 \mathrm{nmol}$ glucose equivalents per hour at $540 \mathrm{~nm}$, and expressed as $\mathrm{U} \mathrm{h}^{-1} \mathrm{~g}^{-1} \mathrm{FW}$.

\subsection{Statistical Analysis}

Three biological replicates per treatments were done, and the effect of $\mathrm{CH}$-HFE coating on "Newhall" navel orange preservation was analyzed using variance analysis $(p<0.05)$. Duncan's multiple range test was used to determine the mean differences. The data are represented as the mean with standard error (SE); these were calculated from physical and chemical experiments, which were performed in three replications.

\section{Results and Discussion}

\subsection{Decay Rate and Weight Loss}

Decay rate is a distinctly important indicator that affects the preservation effect of horticultural produces. As shown in Figure 2A, CH-HFE and 1.5\% chitosan coatings delayed the appearance of fungal infection in comparison to uncoated group, which started to decay from 60 days of storage. Many of the uncoated orange fruits $(10.4 \%)$ were rotten at the termination of storage, while fruits treated by $\mathrm{CH}-\mathrm{HFE}$ and $1.5 \%$ chitosan coating exhibited significantly lower decay rate than the control group at the level of $p<0.05$ (5.2\% and 6.8\%, respectively). As the data in Figure 2B show, for the whole time of experiment, the percentage of weight loss in control group was higher than in both coating treatments, with high weight loss $(9.12 \%)$ of uncoated orange fruits at the end of storage. However, 
orange fruits treated with $\mathrm{CH}-\mathrm{HFE}$ coating displayed the lowest weight loss at $5.16 \%$, which was much lower than that of $1.5 \%$ chitosan and control fruits throughout the 120 -day storage period.
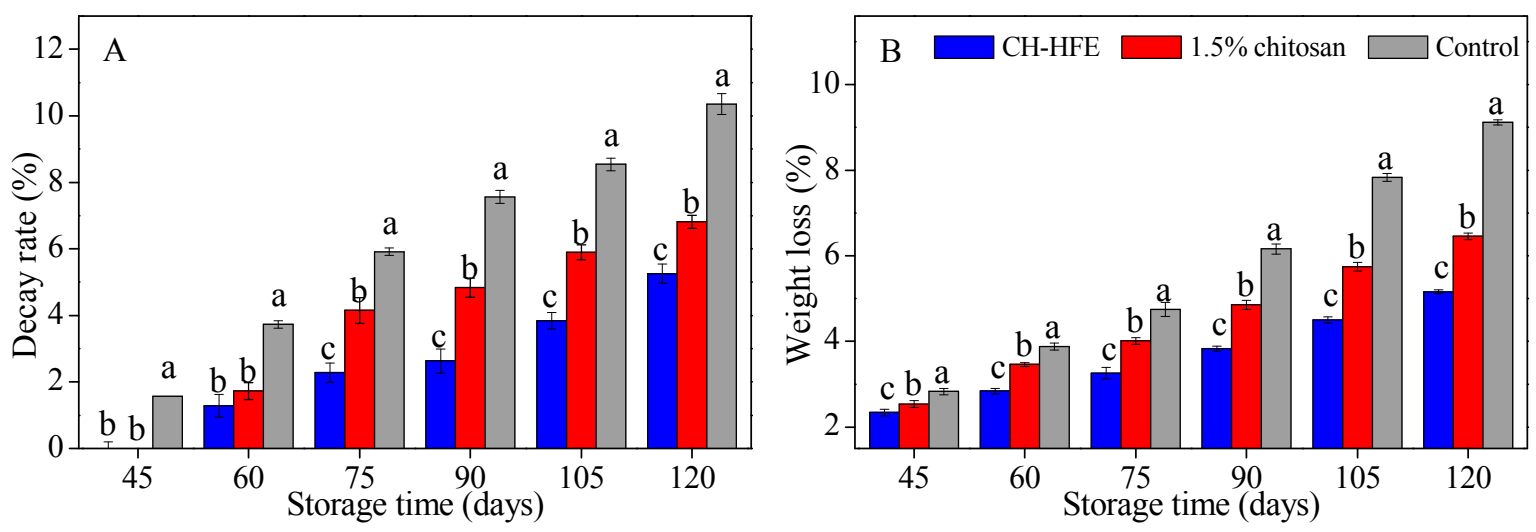

Figure 2. Changes in decay rate (A) and weight loss (B) of navel orange fruits stored at $5{ }^{\circ} \mathrm{C}$ for 120 days. Bars indicate standard error of three replicates.

\subsection{Fruit Quality}

TSS, TA, total sugar, and VC were the key determinants of citrus fruit quality. Figure 3 showed that the content of TSS, TA, total sugar, and VC varied within coated and uncoated groups as storage progressed. As illustrated in Figure 3A,C, the content of TSS and total sugar increased continuously during the early stage of storage, and decreased slightly in the subsequent storage period. The content of TSS and total sugar in the control group reached the highest level at 30 days, while the content of TSS and total sugar in coating groups reached their peaks at 60 days, and were delayed for 30 days more than the control group. During the late 60 days of storage stage, the content of TSS and total sugar in coated fruits was significantly higher $(p<0.05)$ than the control group. The TA content of all samples fell greatly after 120 days of storage (Figure 3B), and the value was significantly higher $(p<0.05)$ in $\mathrm{CH}-\mathrm{HFE}-\mathrm{coated}$ treated fruit, compared to $1.5 \%$ chitosan coating and the control group. During the storage, the control group showed a greater TA loss. The low level of TA in the control group, relative to coating treatments, suggested that the coating delayed ripening by providing a semi-permeable film around the fruits. The CH-HFE and 1.5\% chitosan-coated fruits showed a slight increase in VC content during the first 30 days, reached their peak concentration $(56.87 \mathrm{mg} / 100 \mathrm{~g}$ and $54.04 \mathrm{mg} / 100 \mathrm{~g})$, followed by a decline in the subsequent storage period, while the control group presented a gradual decrease in VC content during the whole storage (Figure 3D). Under the storage conditions, the VC content in CH-HFE coated fruits was significantly higher $(p<0.05)$ than $1.5 \%$ chitosan-coated and control group fruits.

\subsection{Respiration Rate and MDA Content}

As illustrated in Figure 4A, the respiration rate decreased gradually, and reached its valley value at 60 days after storage, and recovered in the subsequent storage period. The valley value in coating-treated fruits was significantly lower $(p<0.05)$ than that in control group. During storage, the respiration rate of $\mathrm{CH}-\mathrm{HFE}$-coated fruits was significantly lower $(p<0.05)$ than those with $1.5 \%$ chitosan coating and the control group.

MDA is the final product of lipid peroxidation, and its content has been used as one of the direct indexes of cell oxidative damage [27]. As shown in Figure 4B, MDA content increased during storage, and a significant difference was shown between the coating treatments and the control group. At the end of the storage (120 days), the MDA content of $\mathrm{CH}-\mathrm{HFE}, 1.5 \%$ chitosan, and control groups reached their maximum $\left(2.47,2.85\right.$, and $3.25 \mathrm{mmol} \mathrm{g}^{-1}$, respectively). The MDA content of control fruits was significantly higher than that of CH-HFE and $1.5 \%$ chitosan coatings, $23.7 \%$ and $12.3 \%$, respectively. 

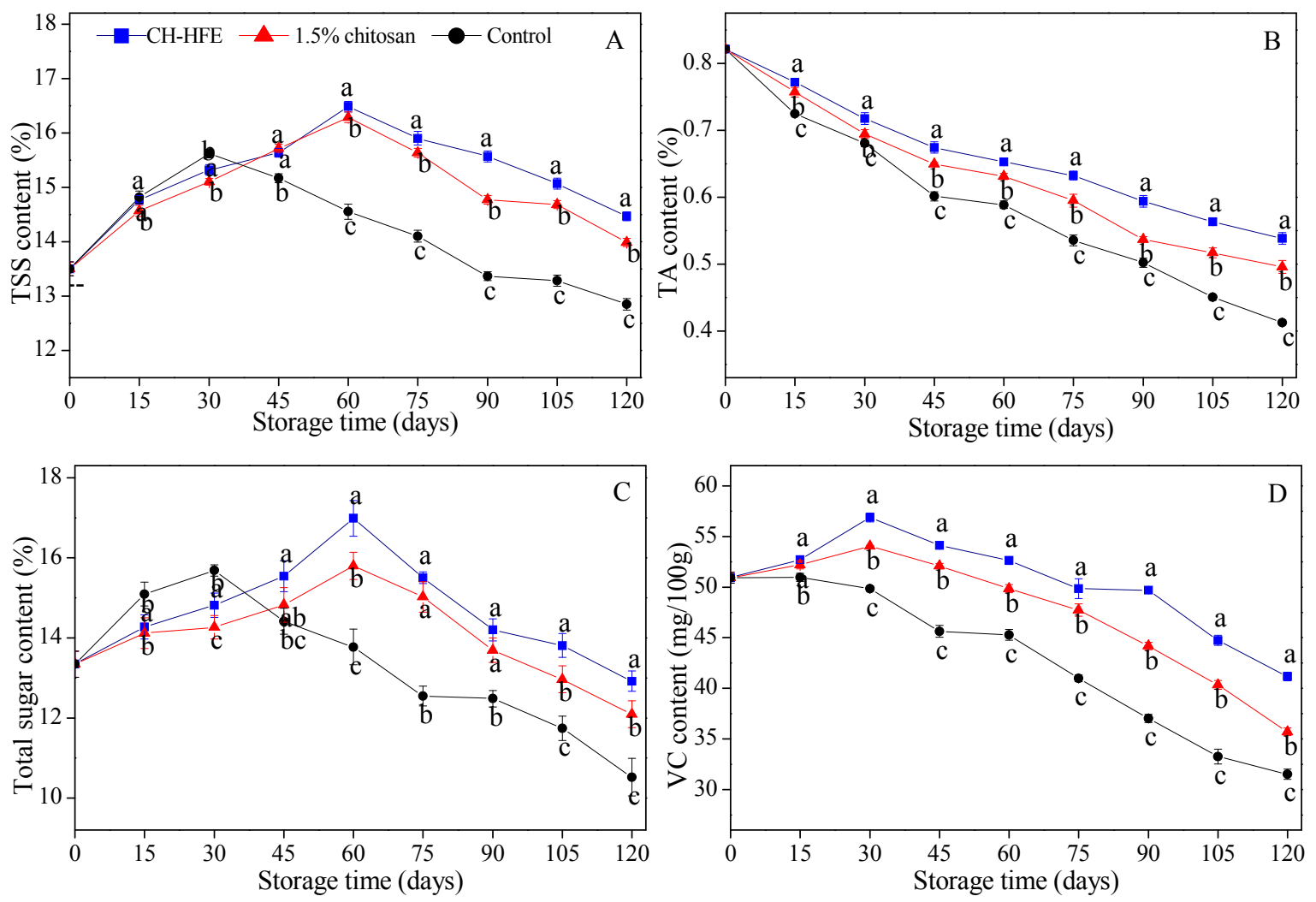

Figure 3. Changes in total soluble solid (TSS) (A), titratable acid (TA) (B), total sugar (C), and vitamin C (VC) content (D) of navel orange fruits stored at $5{ }^{\circ} \mathrm{C}$ for 120 days. Each value represents the mean $\pm \mathrm{SE}$ of three replicates, each consisting of 30 randomly selected fruits.

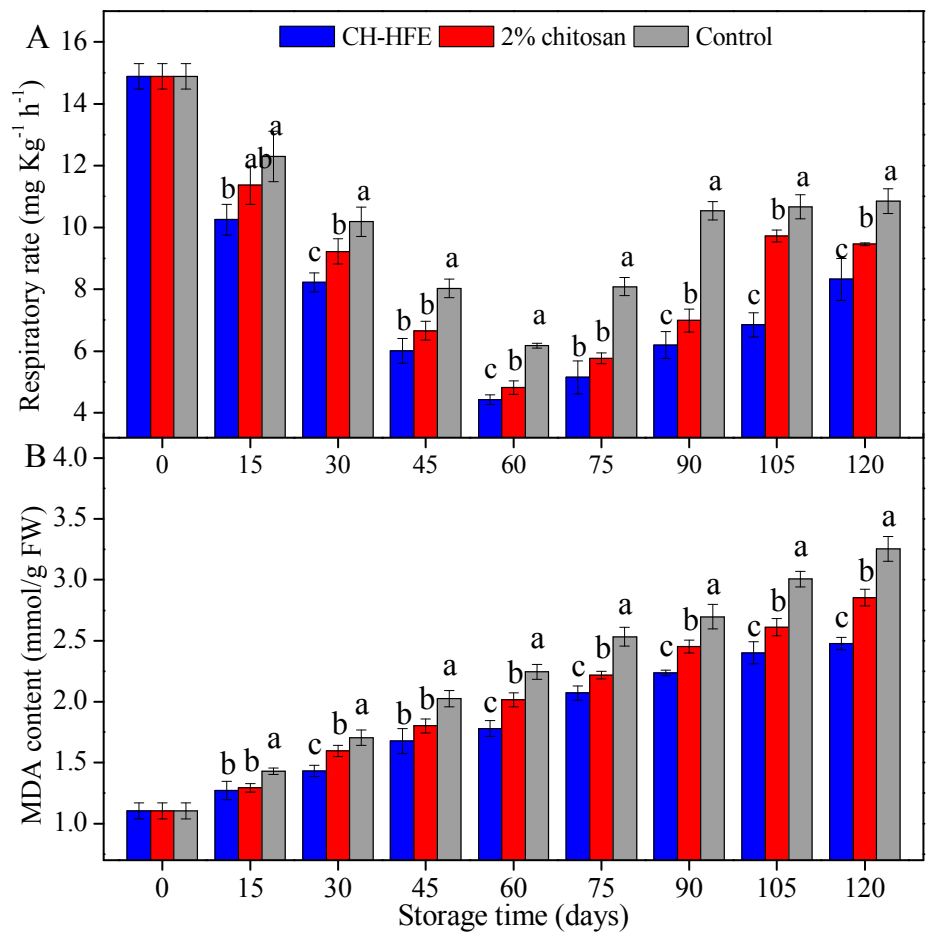

Figure 4. Changes in respiration rate (A) and malondialdehyde (MDA) content (B) of navel orange fruits stored at $5{ }^{\circ} \mathrm{C}$ for 120 days. Bars indicate standard error of three replicates, each consisting of 30 randomly selected fruits. 


\subsection{Activities of Protective Enzymes}

SOD, POD, CHI, and GLU were the main protective enzymes to alleviate lipid peroxidation and delay fruit senescence. Figure 5 showed the activities of SOD, POD, CHI, and GLU varied within coated and uncoated groups, as storage progressed. As illustrated in Figure 5A,B, the activities of SOD and POD gradually increased to reach their peak, and then dropped quickly for the following day. The activities of SOD and POD in the control group reached peak values at 30 days and 60 days, while peak values of SOD and POD activities in coating groups were significantly higher $(p<0.05)$ than the control group, and delayed for 30 days. Moreover, SOD and POD activities in the CH-HFE coated fruits was significantly higher $(p<0.05)$ than those with $1.5 \%$ chitosan coating and the control group, during the later stage of storage. The $\mathrm{CHI}$ activity decreased slightly during the first 30 days, and then increased notably at the end of storage period (Figure 5C). The coated fruits had a relatively high $\mathrm{CHI}$ activity, and the average activity of $\mathrm{CHI}$ of the $\mathrm{CH}-\mathrm{HFE}$ and $1.5 \%$ chitosan-coated treatment increased to approximately 1.30 and 1.19 times higher than that in the control group. The GLU activity of all samples fell greatly after 120 days of storage (Figure 5D), and the value was significantly higher $(p<0.05)$ in $\mathrm{CH}-\mathrm{HFE}-\mathrm{coated}$ treated fruit compared to $1.5 \%$ chitosan coating and the control group.
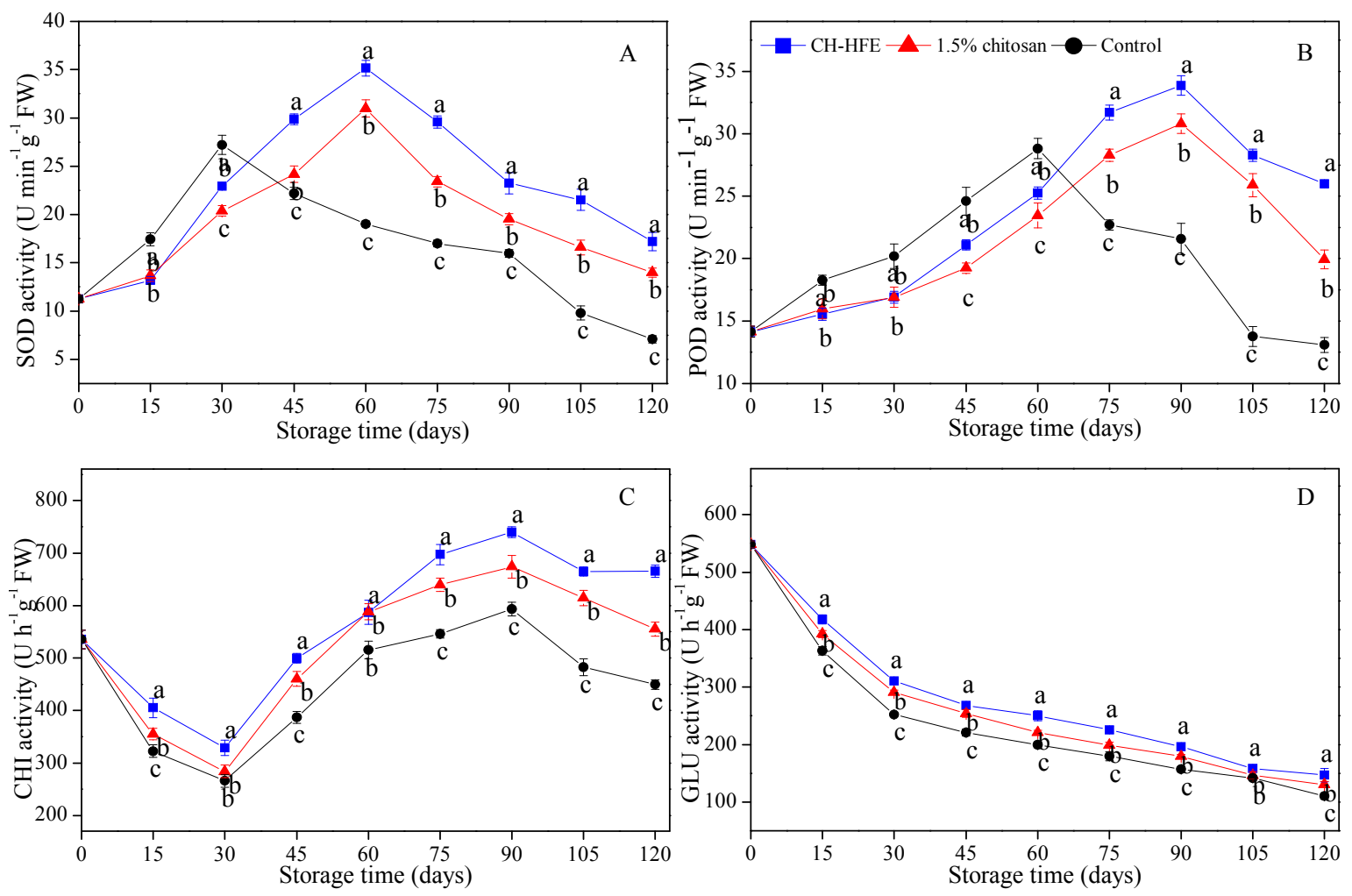

Figure 5. Changes in the activities of SOD (A), POD (B), CHI (C), and GLU (D) of navel orange fruits stored at $5{ }^{\circ} \mathrm{C}$ for 120 days. Each value represents the mean $\pm \mathrm{SE}$ of three replicates selected randomly from 30 fruits each treatment.

\section{Discussion}

As a medicinal plant and food, hairy fig (Ficus hirta Vahl.) fruits have strong antifungal, antioxidant, and antiseptic effects $[28,29]$. Our previous studies have been demonstrated that HFE was able to significantly inhibit both P. italicum and P. digitatum in vitro [21,30]. In the present work, we found that HFE had an abundance of antioxidants and more effective DPPH, OH, ABTS radical scavenging activities, and $\mathrm{Fe}^{3+}$ reducing power than ascorbic acid in different solvent extracts (data not shown). A similar result has been reported where the roots of Ficus hirta Vahl. showed prominent anti-inflammatory activity [31]. A recent in vitro test has shown that HFE had a broad antifungal 
spectrum and high efficacy in controlling fungal growth of fungal pathogens, such as P. italicum, P. digitatum, and Geotrichum citri-aurantii and Alternaria citri in citrus, Botryosphaeria dothidea, Phomopsis sp., and Botrytis cinerea in kiwifruits, Alternaria alternata in pears, and Phomopsis vexans in eggplants [21]. HFE has been shown to be a natural and safe fungistat when applying to control blue mold in citrus, and incorporated into alginate-based edible coatings to enhance Nanfeng mandarin preservation [28]. According to these results, there is no doubt that HFE can be safely used as a natural preservative for horticultural products.

Decay rate and weight loss are the main distinctly important indicators that affect the preservation effect of fresh fruit and vegetables, mainly due to postharvest diseases by pathogen infection, and the loss of water caused by transpiration [32,33]. Edible coatings provide a semi-permeable film around fruit, reducing disease incidence and depressing the rate of dehydration and respiration [28,34]. Coating "Newhall" navel oranges with CH-HFE is clearly effective in conferring a beneficial barrier to pathogen infection and water loss; thus, the decreased rate of fruit decay and weight loss in $\mathrm{CH}-\mathrm{HFE}-\mathrm{coated}$ fruit was evaluated during cold storage in this study. Our results are supported by Shah et al. [35], where fruit rotting intensity and weight loss of Kinnow mandarin can be reduced by coating with carboxymethyl cellulose (CMC) or guar gum-based coatings enriched with silver nanoparticles. Apart from citrus fruit, chitosan-based coatings containing natural antifungal agents, such as plant extracts or essential oils, have been effective at controlling the rate of fruit decay and weight loss from other horticultural products, including strawberry [36-39], guava [40,41], grape [42-44], tomato, and cucumber [45-47].

In general, TSS and TA, known as a respiration substrate, are continually consumed, and affect firsthand the taste flavor of navel oranges. Meanwhile, VC is a nutritional component of citrus fruits, and is also an important antioxidant which scavenges active oxygen. Due to the post-maturing action of citrus fruit, the fruit quality of harvested "Newhall" navel oranges, after a certain period of storage time, was improved, and the content of nutritional components were also increased. As the film acts as a gas barrier, the respiration process slows down the consumption of nutritional components, thus, coating treatment has a positive effect on the increase or maintenance of $\mathrm{VC}$ and other components [33]. In the present study, we found that the changes of $\mathrm{CH}-\mathrm{HFE}$ and $1.5 \%$ chitosan coatings on nutritional components, such as TSS, TA, and total sugar of "Newhall" navel oranges are probably due to the slowing down of respiration, hence effectively delaying fruit ripening and senescence. It is shown by us, that $\mathrm{CH}-\mathrm{HFE}$ and $1.5 \%$ chitosan coatings result in a beneficial semi-permeable film surrounding the fruit, modifying the internal atmosphere by elevating $\mathrm{CO}_{2}$ and/or reducing $\mathrm{O}_{2}$, and delaying the degradation rate of nutritional components in navel orange fruits during the mid-later storage period. Our results are in accordance with those of Chen et al. [23] and Shah et al. [35], where a slow decline in TSS, TA, and VC was recorded in citrus fruits treated with CMC composite coatings. However, other studies have demonstrated that the levels of total soluble solids and acidity, and flavor preferences in "Navel" oranges and "Star Ruby" grapefruits treated with CMC/chitosan bilayer coating, were the same as in the uncoated fruits [48].

Coated "Newhall" oranges generally had lower respiration rate than the uncoated fruits (Figure 5A), likely due to the modification of internal atmosphere by elevating $\mathrm{CO}_{2}$ and/or reducing $\mathrm{O}_{2}$ [28]. Similar observations have been reported by Arnon et al. [48], Chien et al. [49], Contreras-Oliva et al. [50], and Xu et al. [51] in citrus fruits coated with chitosan-based edible coatings. In our research, the incorporation of HFE into $1.5 \%$ chitosan coating formulation resulted in a significantly lower respiration rate than $1.5 \%$ chitosan coating alone, and uncoated fruits, during the whole storage. Similarly, the respiration rate of citrus fruits coated with CMC edible coatings containing clove oil, Impatiens balsamina L. extract, and silver nanoparticles, has been shown to decrease, compared to uncoated fruits $[23,35,52]$.

In this present study, the activities of protective enzymes, such as SOD, POD, CHI, and GLU, are enhanced by $\mathrm{CH}-\mathrm{HFE}$ coating, which suggests that $\mathrm{CH}-\mathrm{HFE}$ coating induces natural resistance in "Newhall" orange fruit by activating the fruit's antioxidant and defense-related system to control the 
level of reactive oxygen species (ROS) and delay fruit senescence (Figure 5A-D). Chen et al. [21,28] and Zeng et al. [18] have also found that Ficus hirta Vahl. extracts have a powerful antifungal activity against Penicillium spp. and abundant antioxidants, as well as inhibitory efficacy for HeLa cells. Chen and co-authors also maintain that an alginate-based edible coating containing HFE can significantly increase the activities of antioxidant and defense-related enzymes and enhance the preservation effect of Nanfeng mandarin [28]. An advantage of the activities of protective enzymes has been reported, previously, for navel oranges treated with a $1.5 \% \mathrm{CMC}$ coating enriched with Impatiens balsamina L. extract, strawberry treated with a $1.0 \%$ chitosan coating containing lemon essential oil, guava treated with $2.0 \%$ sodium alginate and $1.0 \%$ chitosan coatings enriched with pomegranate peel extract, and cherry tomato treated with a $1.0 \%$ chitosan coating incorporating grapefruit seed extract $[37,40,46,52]$. Thus, our results may imply that these different protective enzymes in the antioxidant and defense-related system may be collectively induced by $\mathrm{CH}-\mathrm{HFE}$ coating in navel orange fruits. The induced activities of protective enzymes may be a crucial part of the mechanism of $\mathrm{CH}-\mathrm{HFE}$ coating in enhancing disease resistance and prolonging storage-life for navel orange preservation.

\section{Conclusions}

Edible coatings containing natural antifungal agents, such as plant extracts and essential oils, are being used widely to enhance the preservation effect of horticultural products by prolonging their storage life. In this study, our work indicates that the application of plant extracts, such as hairy fig fruit extract (HFE) with chitosan, could enhance the postharvest quality of navel orange. A combination of HFE into chitosan-based coatings not only resulted in a lower percentage of rotting fruits and weight loss, but also in maintenance of good fruit quality of navel orange, by depressing the respiration rate and, thereby, delaying fruit senescence. Moreover, protective enzymes, including SOD, POD, CHI, and GLU in CH-HFE coating treatment, had obviously higher than those activities of the control group or $1.5 \%$ chitosan coating alone. According to the results from this study, CH-HFE coating treatment showed the best preservation effect for harvested "Newhall" navel orange. The probable preservation mechanism of $\mathrm{CH}$-HFE coating of navel oranges is mainly through reducing the percentage of fruit decay, weight loss, and MDA content, depressing the respiration rate, and maintaining a high level of fruit quality and protective enzymes. In short, our work indicates that $\mathrm{CH}-\mathrm{HFE}$ coating has become a natural and safe alternative treatment for enhancing postharvest quality and prolonging the storage life of navel orange.

Author Contributions: Conceptualization, J.C. and W.C.; Methodology, C.C. and X.P.; Data Analysis, C.C. and Z.N.; Writing-Original Draft Preparation, C.C.; Writing-Review and Editing, W.C.; Project Administration, J.C.; Funding Acquisition, J.C., C.C. and W.C.

Funding: This research was funded by National Natural Science Foundation of China (No. 31760598), and Natural Science Foundation and Advantage Innovation Team Project of Jiangxi Province (No. 20171BAB214031 and No. 20181BCB24005).

Conflicts of Interest: The authors declare no conflict of interest.

\section{References}

1. Palma, A.; D'Aquino, S.; Vanadia, S.; Angioni, A.; Schirra, M. Cold quarantine responses of 'Tarocco' oranges to short hot water and thiabendazole postharvest dip treatments. Postharvest Biol. Technol. 2013, 78, $24-33$. [CrossRef]

2. Zeng, K.; Deng, Y.; Ming, J.; Deng, L. Induction of disease resistance and ROS metabolism in navel oranges by chitosan. Sci. Hortic. 2010, 126, 223-228. [CrossRef]

3. Moscoso-Ramírez, P.A.; Montesinos-Herrero, C.; Palou, L. Control of citrus postharvest Penicillium molds with sodium ethylparaben. Crop Prot. 2013, 46, 44-51. [CrossRef] 
4. Montesinos-Herrero, C.; Smilanick, J.L.; Tebbets, J.S.; Walse, S.; Palou, L. Control of citrus postharvest decay by ammonia gas fumigation and its influence on the efficacy of the fungicide imazalil. Postharvest Biol. Technol. 2011, 59, 85-93. [CrossRef]

5. Smilanick, J.L.; Sorenson, D. Control of postharvest decay of citrus fruit with calcium polysulfide. Postharvest Biol. Technol. 2001, 21, 157-168. [CrossRef]

6. Hao, W.; Zhong, G.; Hu, M.; Luo, J.; Weng, Q.; Rizwan-ul-Haq, M. Control of citrus postharvest green and blue mold and sour rot by tea saponin combined with imazalil and prochloraz. Postharvest Biol. Technol. 2010, 56, 39-43. [CrossRef]

7. D'Aquino, S.; Fadda, A.; Barberis, A.; Palma, A.; Angioni, A.; Schirra, M. Combined effects of potassium sorbate, hot water and thiabendazole against green mould of citrus fruit and residue levels. Food Chem. 2013, 141, 858-864. [CrossRef] [PubMed]

8. Talibi, I.; Boubaker, H.; Boudyach, E.; Ait Ben Aoumar, A. Alternative methods for the control of postharvest citrus diseases. J. Appl. Microbiol. 2014, 117, 1-17. [CrossRef]

9. Da Cruz Cabral, L.; Fernández Pinto, V.; Patriarca, A. Application of plant derived compounds to control fungal spoilage and mycotoxin production in foods. Int. J. Food Microbiol. 2013, 166, 1-14. [CrossRef]

10. Karim, H.; Boubaker, H.; Askarne, L.; Cherifi, K.; Lakhtar, H.; Msanda, F.; Boudyach, E.H.; Ait Ben Aoumar, A. Use of Cistus aqueous extracts as botanical fungicides in the control of Citrus sour rot. Microb. Pathog. 2017, 104, 263-267. [CrossRef]

11. Palou, L.; Ali, A.; Fallik, E.; Romanazzi, G. GRAS, plant- and animal-derived compounds as alternatives to conventional fungicides for the control of postharvest diseases of fresh horticultural produce. Postharvest Biol. Technol. 2016, 122, 41-52. [CrossRef]

12. Tripathi, P.; Dubey, N.K. Exploitation of natural products as an alternative strategy to control postharvest fungal rotting of fruit and vegetables. Postharvest Biol. Technol. 2004, 32, 235-245. [CrossRef]

13. Camele, I.; Altieri, L.; De Martino, L.; De Feo, V.; Mancini, E.; Rana, G.L. In vitro control of post-harvest fruit rot fungi by some plant essential oil components. Int. J. Mol. Sci. 2012, 13, 2290-2300. [CrossRef] [PubMed]

14. Li Destri Nicosia, M.G.; Pangallo, S.; Raphael, G.; Romeo, F.V.; Strano, M.C.; Rapisarda, P.; Droby, S.; Schena, L. Control of postharvest fungal rots on citrus fruit and sweet cherries using a pomegranate peel extract. Postharvest Biol. Technol. 2016, 114, 54-61. [CrossRef]

15. Vitoratos, A.; Bilalis, D.; Karkanis, A.; Efthimiadou, A. Antifungal Activity of Plant Essential Oils Against Botrytis cinerea, Penicillium italicum and Penicillium digitatum. Not. Bot. Horti Agrobot. 2013, 41, 86-92. [CrossRef]

16. Jhalegar, M.J.; Sharma, R.R.; Singh, D. In vitro and in vivo activity of essential oils against major postharvest pathogens of Kinnow (Citrus nobilis $\times$ C. deliciosa) mandarin. J. Food Sci. Technol. 2015, 52, $2229-2237$. [CrossRef]

17. Askarne, L.; Talibi, I.; Boubaker, H.; Boudyach, E.; Msanda, F.; Saadi, B.; Serghini, M.; Ait Ben Aoumar, A. In vitro and in vivo antifungal activity of several Moroccan plants against Penicillium italicum, the causal agent of citrus blue mold. Crop Prot. 2012, 40, 53-58. [CrossRef]

18. Zeng, Y.W.; Liu, X.Z.; Lv, Z.C.; Peng, Y.H. Effects of Ficus hirta Vahl. (Wuzhimaotao) extracts on growth inhibition of HeLa cells. Exp. Toxicol. Pathol. 2012, 64, 743-749. [CrossRef]

19. Ya, J.; Zhang, X.Q.; Wang, Y.; Zhang, Q.W.; Chen, J.X.; Ye, W.C. Two new phenolic compounds from the roots of Ficus hirta. Nat. Prod. Res. 2010, 24, 621-625. [CrossRef]

20. Wan, C.P.; Chen, C.Y.; Li, M.X.; Yang, Y.X.; Chen, M.; Chen, J.Y. Chemical constituents and antifungal activity of Ficus hirta Vahl. fruits. Plants 2017, 6, 44. [CrossRef]

21. Chen, C.Y.; Wan, C.P.; Peng, X.; Chen, Y.H.; Chen, M.; Chen, J.Y. Optimization of antifungal extracts from Ficus hirta fruits using response surface methodology and antifungal activity tests. Molecules 2015, 20, 19647-19659. [CrossRef] [PubMed]

22. Helrich, K. Official Methods of Analysis of the Association of Official Analytical Chemists; Association of Official Analytical Chemists: Arlington, VA, USA, 1990.

23. Chen, C.Y.; Zheng, J.P.; Wan, C.P.; Chen, M.; Chen, J.Y. Effect of carboxymethyl cellulose coating enriched with clove oil on postharvest quality of 'Xinyu' mandarin oranges. Fruits 2016, 71, 319-327. [CrossRef]

24. Hodges, D.M.; DeLong, J.M.; Forney, C.F.; Prange, R.K. Improving the thiobarbituric acid-reactive-substances assay for estimating lipid peroxidation in plant tissues containing anthocyanin and other interfering compounds. Planta 1999, 207, 604-611. [CrossRef] 
25. Sala, J.M.; Lafuente, M.A.T. Antioxidant enzymes activities and rindstaining in 'Navelina'oranges as affected by storage relative humidity and ethylene conditioning. Postharvest Biol. Technol. 2004, 31, $277-285$. [CrossRef]

26. Abeles, F.B.; Bosshart, R.P.; Forrence, L.E.; Habig, W.H. Preparation and purification of glucanase and chitinase from bean leaves. Plant Physiol. 1971, 47, 129-134. [CrossRef] [PubMed]

27. Xu, W.T.; Peng, X.L.; Luo, Y.B.; Wang, J.A.; Guo, X.; Huang, K.L. Physiological and biochemical responses of grapefruit seed extract dip on 'Redglobe' grape. LWT Food Sci. Technol. 2009, 42, 471-476. [CrossRef]

28. Chen, C.Y.; Peng, X.; Zeng, R.; Chen, M.; Wan, C.P.; Chen, J.Y. Ficus hirta fruits extract incorporated into an alginate-based edible coating for Nanfeng mandarin preservation. Sci. Hortic. 2016, 202, 41-48. [CrossRef]

29. Yi, T.; Chen, Q.L.; He, X.C.; So, S.W.; Lo, Y.L.; Fan, L.L.; Xu, J.; Tang, Y.; Zhang, J.Y.; Zhao, Z.Z. Chemical quantification and antioxidant assay of four active components in Ficus hirta root using UPLC-PAD-MS fingerprinting combined with cluster analysis. Chem. Cent. J. 2013, 7, 1752-1760. [CrossRef] [PubMed]

30. Wan, C.; Han, J.; Chen, C.; Yao, L.; Chen, J.; Yuan, T. Monosubstituted benzene derivatives from fruits of Ficus hirta and their antifungal activity against phytopathogen Penicillium italicum. J. Agric. Food Chem. 2016, 64, 5621-5624. [CrossRef] [PubMed]

31. Cheng, J.; Yi, X.; Wang, Y.; Huang, X.; He, X. Phenolics from the roots of hairy fig (Ficus hirta Vahl.) exert prominent anti-inflammatory activity. J. Funct. Foods 2017, 31, 79-88. [CrossRef]

32. Grande-Tovar, C.D.; Chaves-Lopez, C.; Serio, A.; Rossi, C.; Paparella, A. Chitosan coatings enriched with essential oils: Effects on fungi involve in fruit decay and mechanisms of action. Trends Food Sci. Technol. 2018, 78, 61-71. [CrossRef]

33. Xing, Y.; Xu, Q.; Yang, S.; Chen, C.; Tang, Y.; Sun, S.; Zhang, L.; Che, Z.; Li, X. Preservation mechanism of chitosan-based coating with cinnamon oil for fruits storage based on sensor data. Sensors 2016, 16, 1111. [CrossRef] [PubMed]

34. Sapper, M.; Chiralt, A. Starch-based coatings for preservation of fruits and vegetables. Coatings 2018, 8, 152. [CrossRef]

35. Shah, S.W.A.; Jahangir, M.; Qaisar, M.; Khan, S.A.; Mahmood, T.; Saeed, M.; Farid, A.; Liaquat, M. Storage stability of Kinnow fruit (Citrus reticulata) as affected by CMC and guar gum-based silver nanoparticle coatings. Molecules 2015, 20, 22645-22661. [CrossRef] [PubMed]

36. Velickova, E.; Winkelhausen, E.; Kuzmanova, S.; Alves, V.D.; Moldão-Martins, M. Impact of chitosan-beeswax edible coatings on the quality of fresh strawberries (Fragaria ananassa cv Camarosa) under commercial storage conditions. LWT Food Sci. Technol. 2013, 52, 80-92. [CrossRef]

37. Perdones, A.; Sánchez-González, L.; Chiralt, A.; Vargas, M. Effect of chitosan-lemon essential oil coatings on storage-keeping quality of strawberry. Postharvest Biol. Technol. 2012, 70, 32-41. [CrossRef]

38. Shahbazi, Y. Application of carboxymethyl cellulose and chitosan coatings containing Mentha spicata essential oil in fresh strawberries. Int. J. Biol. Macromol. 2018, 112, 264-272. [CrossRef] [PubMed]

39. Ventura-Aguilar, R.I.; Bautista-Baños, S.; Flores-García, G.; Zavaleta-Avejar, L. Impact of chitosan based edible coatings functionalized with natural compounds on Colletotrichum fragariae development and the quality of strawberries. Food Chem. 2018, 262, 142-149. [CrossRef] [PubMed]

40. Nair, M.S.; Saxena, A.; Kaur, C. Effect of chitosan and alginate based coatings enriched with pomegranate peel extract to extend the postharvest quality of guava (Psidium guajava L.). Food Chem. 2018, 240, 245-252. [CrossRef] [PubMed]

41. Lima Oliveira, P.D.; de Oliveira, K.Á.R.; Vieira, W.A.d.S.; Câmara, M.P.S.; de Souza, E.L. Control of anthracnose caused by Colletotrichum species in guava, mango and papaya using synergistic combinations of chitosan and Cymbopogon citratus (D.C. ex Nees) Stapf. essential oil. Int. J. Food Microbiol. 2018, 266, 87-94. [CrossRef]

42. Sánchez-González, L.; Pastor, C.; Vargas, M.; Chiralt, A.; González-Martínez, C.; Cháfer, M. Effect of hydroxypropylmethylcellulose and chitosan coatings with and without bergamot essential oil on quality and safety of cold-stored grapes. Postharvest Biol. Technol. 2011, 60, 57-63. [CrossRef]

43. Guerra, I.C.D.; de Oliveira, P.D.L.; Santos, M.M.F.; Lúcio, A.S.S.C.; Tavares, J.F.; Barbosa-Filho, J.M.; Madruga, M.S.; de Souza, E.L. The effects of composite coatings containing chitosan and Mentha (Piperita L. or $x$ villosa Huds) essential oil on postharvest mold occurrence and quality of table grape cv. Isabella. Innov. Food Sci. Emerg. Technol. 2016, 34, 112-121. [CrossRef] 
44. Dos Santos, N.S.T.; Athayde Aguiar, A.J.A.; de Oliveira, C.E.V.; Veríssimo de Sales, C.; de Melo e Silva, S.; Sousa da Silva, R.; Stamford, T.C.M.; de Souza, E.L. Efficacy of the application of a coating composed of chitosan and Origanum vulgare L. essential oil to control Rhizopus stolonifer and Aspergillus niger in grapes (Vitis labrusca L.). Food Microbiol. 2012, 32, 345-353. [CrossRef] [PubMed]

45. Athayde, A.J.A.A.; Oliveira, P.D.L.D.; Guerra, I.C.D.; Conceição, M.L.D.; Lima, M.A.B.D.; Arcanjo, N.M.O.; Madruga, M.S.; Berger, L.R.R.; Souza, E.L.D. A coating composed of chitosan and Cymbopogon citratus (Dc. Ex Nees) essential oil to control Rhizopus soft rot and quality in tomato fruit stored at room temperature. J. Hortic. Sci. Biotechnol. 2016, 91, 582-591. [CrossRef]

46. Won, J.S.; Lee, S.J.; Park, H.H.; Song, K.B.; Min, S.C. Edible coating using a chitosan-based colloid incorporating grapefruit seed extract for cherry tomato safety and preservation. J. Food Sci. 2018, 83, 138-146. [CrossRef] [PubMed]

47. Mohammadi, A.; Hashemi, M.; Hosseini, S.M. Postharvest treatment of nanochitosan-based coating loaded with Zataria multiflora essential oil improves antioxidant activity and extends shelf-life of cucumber. Innov. Food Sci. Emerg. 2016, 33, 580-588. [CrossRef]

48. Arnon, H.; Zaitsev, Y.; Porat, R.; Poverenov, E. Effects of carboxymethyl cellulose and chitosan bilayer edible coating on postharvest quality of citrus fruit. Postharvest Biol. Technol. 2014, 87, 21-26. [CrossRef]

49. Chien, P.-J.; Sheu, F.; Lin, H.-R. Coating citrus (Murcott tangor) fruit with low molecular weight chitosan increases postharvest quality and shelf life. Food Chem. 2007, 100, 1160-1164. [CrossRef]

50. Contreras-Oliva, A.; Perez-Gago, M.B.; Rojas-Argudo, C. Effects of chitosan coatings on physicochemical and nutritional quality of clementine mandarins cv. 'Oronules'. Food Sci. Technol. Int. 2012, 18, 303-315. [CrossRef]

51. Xu, D.; Qin, H.; Ren, D. Prolonged preservation of tangerine fruits using chitosan/montmorillonite composite coating. Postharvest Biol. Technol. 2018, 143, 50-57. [CrossRef]

52. Zeng, R.; Zhang, A.S.; Chen, J.Y.; Fu, Y.Q. Impact of carboxymethyl cellulose coating enriched with extract of Impatiens balsamina stems on preservation of 'Newhall' navel orange. Sci. Hortic. 2013, 160, 44-48. [CrossRef]

(C) 2018 by the authors. Licensee MDPI, Basel, Switzerland. This article is an open access article distributed under the terms and conditions of the Creative Commons Attribution (CC BY) license (http:/ / creativecommons.org/licenses/by/4.0/). 